\title{
The Basel Declaration: a critical appraisal
}

The Basel Declaration was adopted at the "Research at a crossroads" conference, held in Basel on November 29, 2010. The Declaration was lauded as "a call for more trust, transparency, and communication on animal research." This initiative must be respected: every attempt to get closer to fair solutions in handling (experimental) animals must be taken seriously and be weighed for its potential value. With all respect, however, such a Declaration must be measured against existing documents formulated by scientists with a serious research interest in this subject. As it is termed the "Basel Declaration," it appears most logical to compare it to the "Ethical Principles and Guidelines for Experiments on Animals (EPGE), $3^{\text {rd }}$ edition 2005," which are available at the websites of the Swiss Academy of Medical Sciences (www.SAMW.ch) and the Swiss Academy of Sciences (www.SCNAT.ch).

The Basel Declaration states that "social and humanitarian challenges" posed by unsolved biomedical problems cannot be overcome without research using animals. As indicated in its introduction, the Declaration permits no differentiation between basic research and applied science but declares, rather, that it "is a continuum stretching from studies of fundamental physiological processes to an understanding of the principles of disease and the development of therapies."

The EPGE, on the other hand, derive their basis from the insight that, although we cannot solve certain scientific problems without animal experiments, such experimentation does pose a conflict with the ethical principles of "respect for life" and respect for the "dignity of creation." The EPGE challenge scientists to find the best possible resolution of this conflict.

\section{Basel Declaration \\ Science requires}

animal experiments

EPGE
Science recognizes
a conflict

In the "Fundamental Principles" the signees of the Basel Declaration commit themselves to ten points, which are really matters of course, reading almost as if it is necessary for scientists to sign a special avowal that they are prepared to follow the law. One does not want to "inflict unnecessary pain, suffering, or harm" (that is required in Animal Protection Law); one will consider whether questions "cannot be answered using alternative methods" (this is compulsory under the EU Directives); one wants to keep animal numbers as low as possible (this is also required by law), etc. Some of the commitments have nothing to do with the well-being of animals but rather with the well-being of scientists, whose engagement should be recognized "adequately ... in their efforts to promote the public understanding of science." One aims to "Promote the dialogue concerning" - not with - "animal welfare in research by transparent and fact-based communications to the public." This makes it appear that the authors think animal welfare has not been informing the public in a transparent and fact-based manner and that the scientists must now rectify this. The 10th aim, i.e., to advise political decision makers and government authorities on "issues of research involving animals and their welfare," adds further irony to this picture of a self-committal. Science, with one of the most effective lobbying systems, has been doing such advising for decades. There is hardly another area where science and industry have as much influence as in the realm of Research, Education, and Health Politics. No wonder signees of the Declaration are happy to commit to continuing in this fashion.

In contrast, the EPGE apply to the real problems. They demand the ethical principle of "respect for life" from every scientist; they recognize the conflicts and name them openly. This fosters trust. They specifically address the 3Rs principle and have respect for the "dignity of creation:" "Any animal experiment that causes pain or stress to the animal basically represents an attack on the dignity of the animal and must, therefore, be justified through the balancing of the ethical concerns involved. If human beings fail to respect the acknowledged dignity of animals, they abuse their freedom and fail to respect their own dignity." Note that the latter two sentences were written not by animal welfare but by the Swiss Academies. The Basel Declaration does not even consider the possibility of situations in which one should decide to forgo the gain in knowledge. The EPGE does (3.5): "Certain experimental set-ups can be expected to cause such severe suffering for animals that the weighing up of ethical concerns will always fall in favor of the animals. If it is not possible to find less harmful and more ethically acceptable test arrangements by changing the research hypothesis, it will be necessary to refrain from carrying out the experiment and to forgo the expected gain in knowledge."

$\begin{array}{cc}\begin{array}{c}\text { Basel Declaration } \\ \text { commits to following } \\ \text { the law }\end{array} & \text { EPGE } \\ \text { demands forgoing knowledge } \\ \text { gain in certain situations }\end{array}$

Of course, the EPGE also formulate committals that are included in national law, i.e., lowest possible animal numbers, 
least possible suffering, forbiddance of substances that induce paralysis without loss of consciousness and without analgesic effects, protective familiarization of the animal with the test conditions, clearly defined termination criteria. But the duty to euthanize in case of serious suffering (4.9) already goes further than the legal obligations. In addition, Swiss scientists attained much trust based on point 5.2 of the EPGE: "Researchers employed in Switzerland shall refrain from carrying out experiments on animals abroad that contravene the Swiss animal welfare legislation and cannot be justified on the basis of these Ethical Principles and Guidelines and from participating in their implementation abroad." This sentence alone demands respect.

The Basel Declaration also exceeds the legal requirements in one point: It encourages a free and transparent exchange to avoid unnecessary duplication of experiments. The EPGE are somewhat more demanding in this respect, stating (5.3): "Persons involved in research are obliged to take and support all possible measures to limit painful and stressful experiments on animals. Persons involved in research are obliged to subject the suitability of all established and officially promoted animal testing methods to regular critical assessment. They are also obliged to promote the exchange of information about the results of experiments on animals so as to avoid unnecessary experiments and, where applicable, to support the updating of regulations and methods."

$\begin{array}{cc}\text { Basel Declaration } & \text { EPGE } \\ \text { encourages avoiding } & \text { obliges to limit animal } \\ \text { duplication } & \begin{array}{c}\text { experiments, also those } \\ \text { prescribed by law }\end{array}\end{array}$

The Basel Declaration falls far short of the obligations that Swiss scientists imposed on themselves voluntarily. It is a list of demands. The signees assume that committing themselves to following the law is sufficient to ratify their right to freedom in science, giving them the right to demand that research with animals, including non-human primates, be continued indefinitely. What the Basel Declaration wholly lacks is an attitude of humility, indicating that the signees understand, at least to some extent, that animal experiments represent a conflict situation per se. Trust can only be won by showing humility accompanied by a willingness to limit oneself. Instead, the Declaration offers only demands, demands, demands.
At least the Basel Declaration invites representatives of animal welfare organizations to openly discuss all important questions with the scientists. One can get the feeling, however, that these open discussions will instead be attempts to instruct animal protectionists. At least the signees of the Basel Declaration do not go so far as to accuse animal protectionists of endangering jobs. In contrast, the EPGE see it as the duty of scientists to educate themselves on animal protection issues (5.4): "Persons involved in scientific research are obliged to do further training in animal welfare and to support the development of alternative research methods." Again we have that clear difference: the Declaration invites discussion, the EPGE commit scientists.

Vehemently demanding trust in a declaration is not the way to win it. The EPGE have contributed far more toward winning trust in science than this Declaration can. It is a shame that the signees of the Declaration obviously were not familiar with the EPGE; a touch of modesty would have helped to formulate a far better declaration.

To avoid misunderstandings: The "Charter on Animal Welfare" of June 20, 2010 also was adopted in Basel. With this Charter, Interpharma, a syndicate of the companies Actelion Ltd \& Actelion Pharmaceuticals Ltd, F. Hoffmann-La Roche Ltd, Merck Serono International S.A., and Novartis Pharma Ltd, commits, among other things, to apply alternative methods and to advance their development and use on an international basis according to the 3Rs Principle. There is nothing wrong with that. Apparently the authors of the Basel Declaration also were unfamiliar with this Charter.

The Basel Declaration was formulated in German, English, French, and Italian, with the aim of reaching a large, international audience. An urgent update of the Declaration is needed to show the world that scientists have more to offer than a promise to follow the law. Perhaps this will be a result of the conference "Pathway to more Transparency in Animal Research" held on October 17-18, 2011 in Berlin (see News item on p. 373).

\author{
Franz P. Gruber \\ Küsnacht $\mathrm{ZH}$ \\ Switzerland \\ fpgruber@grashey.eu
}

